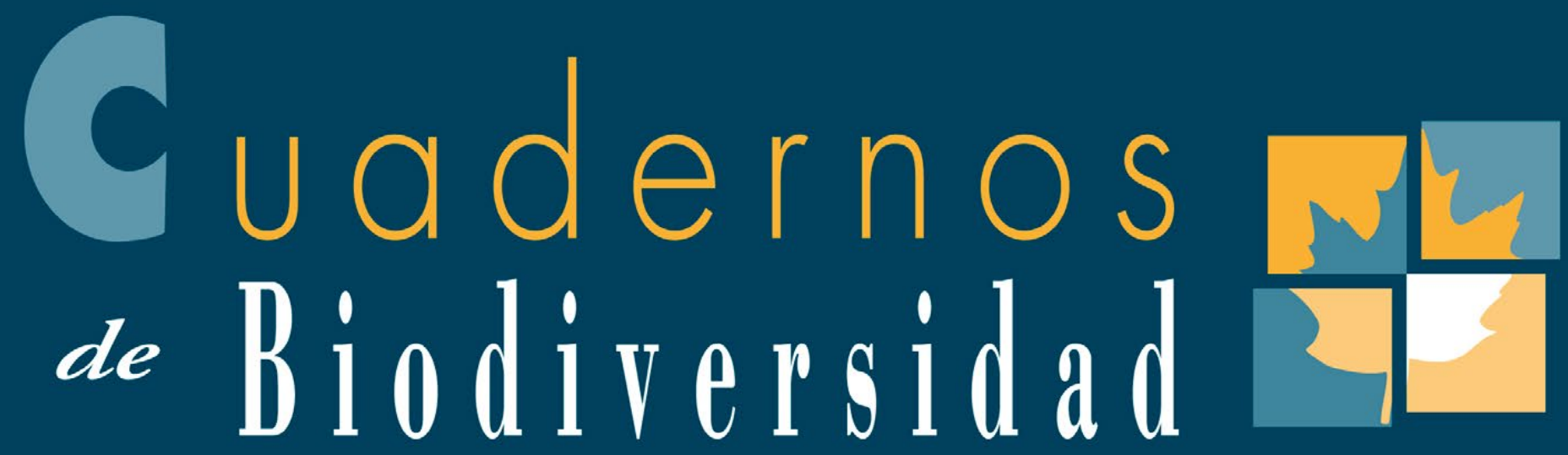

Cuadernos de biodiversidad número $47 \cdot 2015$
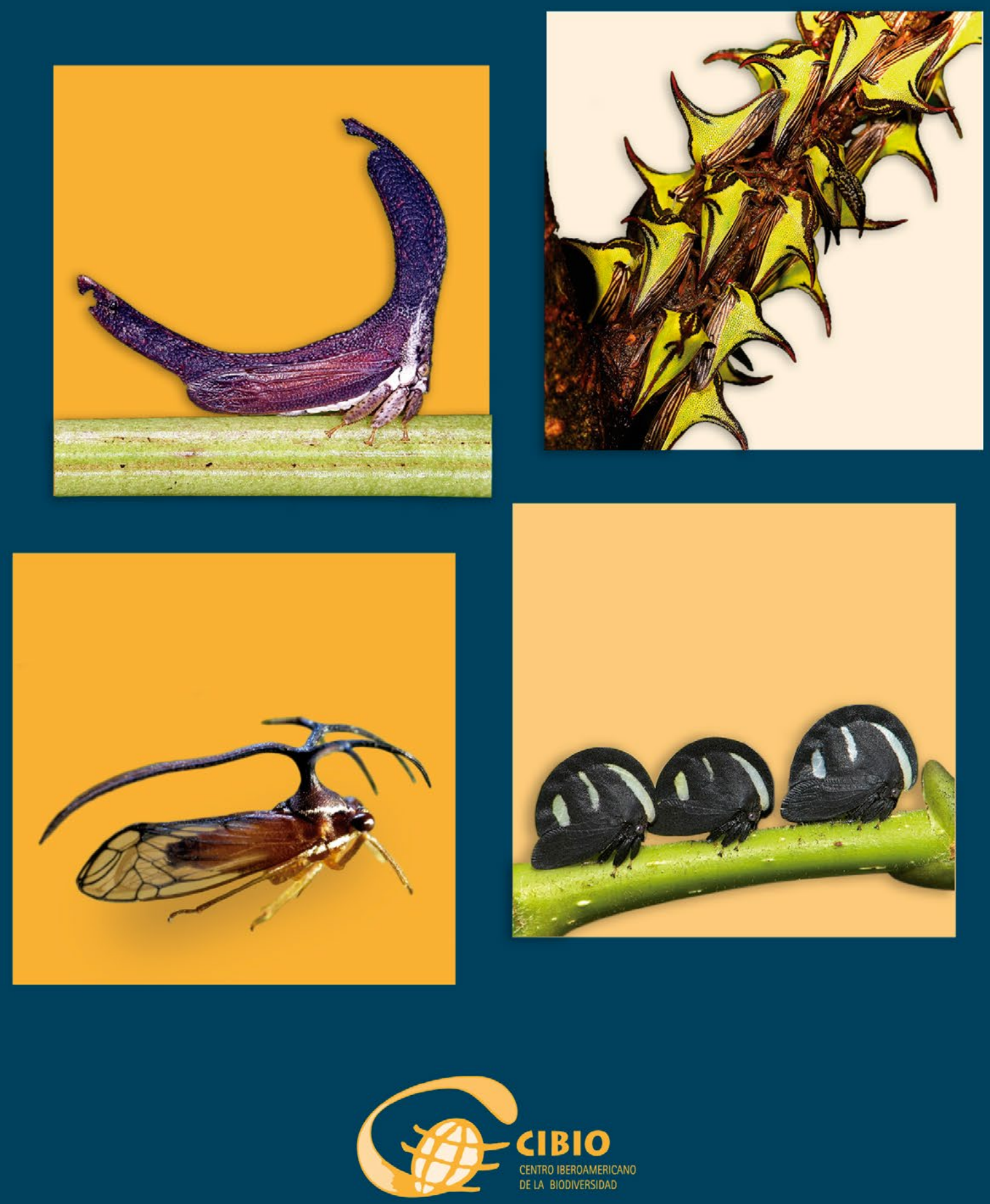

Universitat d'Alacant
Universidad de Alicante 


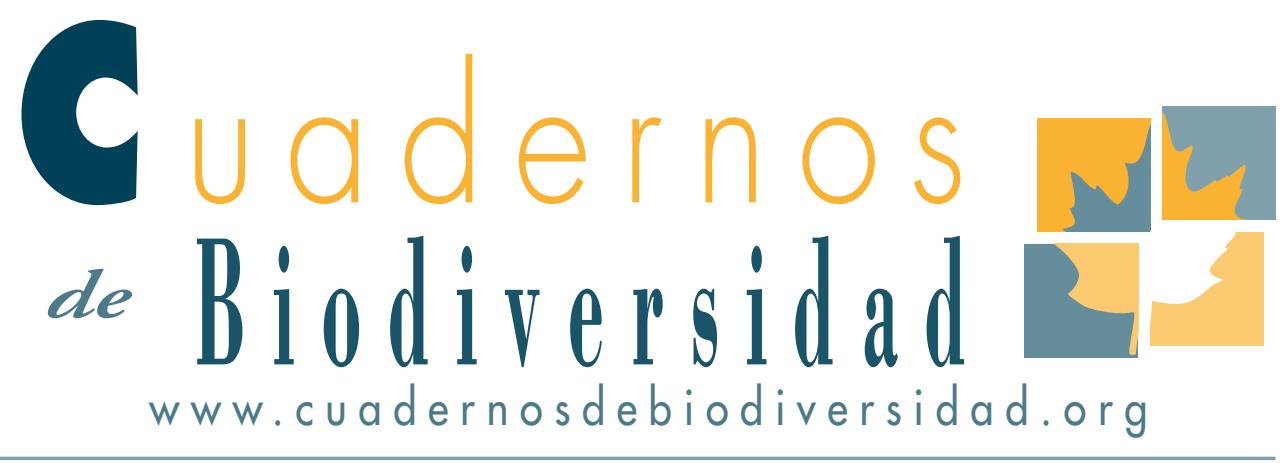

\section{El paisaje del agua}

\section{Sergio Guevara}

Instituto de Ecología de Xalapa, INECOL, Mexico. E-mail: sergio.guevara@inecol.mx

En las arenas de la llanura costera, al sur del Golfo de México, aparece como encallado, con sus aparejos desplegados, un imponente navío de basalto. Empapado por el hálito marino, proyecta su silueta de viento y lluvia en el Sotavento, un horizonte de mástiles que domina el paisaje desde el mar y la tierra adentro.

El colosal buque ha sido esculpido por el sol tropical, el viento incesante y la lluvia que escurre, desde sus velas volcánicas, fraguando el magma en las cuencas, cauces, cañadas y cráteres, sobre los que fluye en torrentes o resbala mansamente hasta disolverse en el mar, en los ríos y los pantanos, entre mariposas y serpientes.

Tres volcanes, son sus arboladuras, que emergen desde la orilla del mar, oponiéndose al viento de barlovento que sube sus laderas y desciende en corrientes y arroyos, en un mosaico de humedad, suelo y calor, donde se recluyen plantas y animales procedentes del sur y del norte que se amalgaman entre sí, en fórmulas de inconcebible riqueza. Y en lo alto del navío isla, en la cima de los volcanes, las atalayas velan los confines de la sierra y del mar.
El agua que flota en el aire y empapa el suelo predispuso el paisaje que forjó la cultura olmeca, dando lugar al mito de Los Tuxtlas, el corazón de Mesoamérica, donde se agitan las entrañas de la tierra y del cielo, donde hombres, plantas y animales se encontraron y desencontraron incansablemente, inventándose entre sí, en una quimera de humedad, luz, sombra, fragor y color. Una epopeya del empeño humano prolongada y vigorosa cuyo desenlace es fascinante como la selva misma.

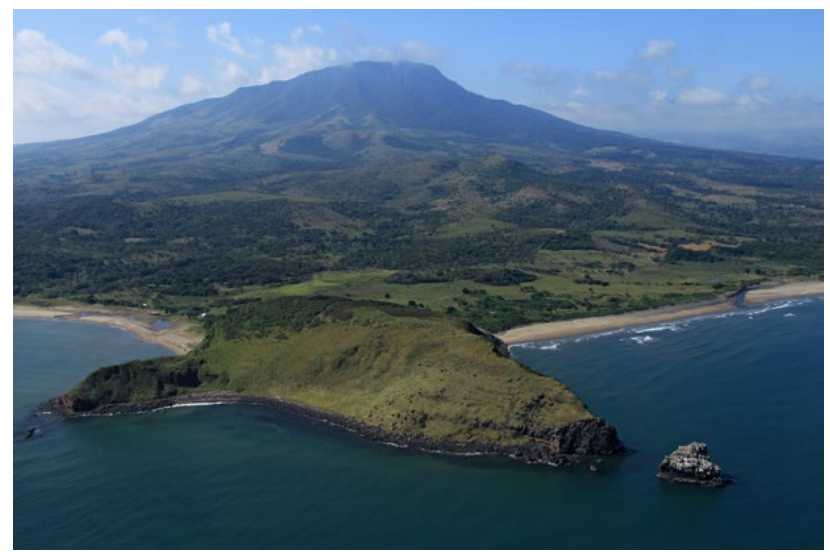

La sierra de Los Tuxtlas desde el mar, al fondo el volcán de San Martín Tuxtla (fotografía cortesía de Gerardo Sánchez Vigil) 
El pacto mitológico entre la sabiduría, la experiencia y la fuerza de los elementos urdió una naturaleza desde las cumbres nubladas de San Martín, Santa Marta y Pajapan, hasta los médanos de la costa y los humedales del San Juan y gestó la leyenda de un infinito de abundancia, frescura y verdor, de una primavera interminable, el Tlalocan, custodiado por deidades mayores y menores, amos de las plantas, los animales, el agua y la montaña. En su umbral están los acahuales y los inmensos árboles solitarios, donde se resguarda la esencia de la selva y del conocimiento de los hombres.

Desde allí los chaneques gobiernan a los animales que corren y vuelan desde la alborada al ocaso y en las tinieblas, acarreando a la selva en patas y picos. Son los centinelas de la sierra, los árboles que la selva dejó atrás, para indicar el principio y el fin de los campos, mantener la penumbra de los cursos de agua y dar reposo y abrigo a las plantas y animales de la selva que retan al espacio inhóspito en su azarosa búsqueda de los acahuales y los límites del paisaje.

Parecería que la selva flotara en el aire, las plantas y los animales rondan el espacio y el tiempo, aparecen, permanecen y desaparecen rápida o lentamente, en armonía con la perturbación, se disimulan en el suelo, escapan en el viento o se acompañan unos a otros en una interminable exploración de hábitats de la selva por fuera de la selva.

En la distancia, la sierra ha guiado a los caminantes y navegantes a través de los ríos, humedales y caminos de Sotavento, a lo largo de la costa, las lagunas y las desembocaduras y aún desde mar adentro. Se reconoce como el paradigma del conocimiento y la cultura del mundo mesoamericano; ha sido inexpugnable para los extraños, ocultándose tras una empalizada de selva, de árboles densos y recios que la cierran desde la orilla del mar y la tierra baja, mientras en las entrańas de Los Tuxtlas la vida deambula sigilosamente por los caminos de agua, insinuados por puertos casi invisibles, en la costa y la ribera de ríos y lagunas.

Cuando la descubrieron los blancos, la vieron como un enclave de verdor y exuberancia, la tierra prometida, de inmensas extensiones feraces y despobladas, legendaria por su intensa actividad volcánica y sísmica, una fortuna de riquezas naturales, al que penetraron por nuevos caminos, abiertos por el ganado, que se adentró en la sierra, descubriendo

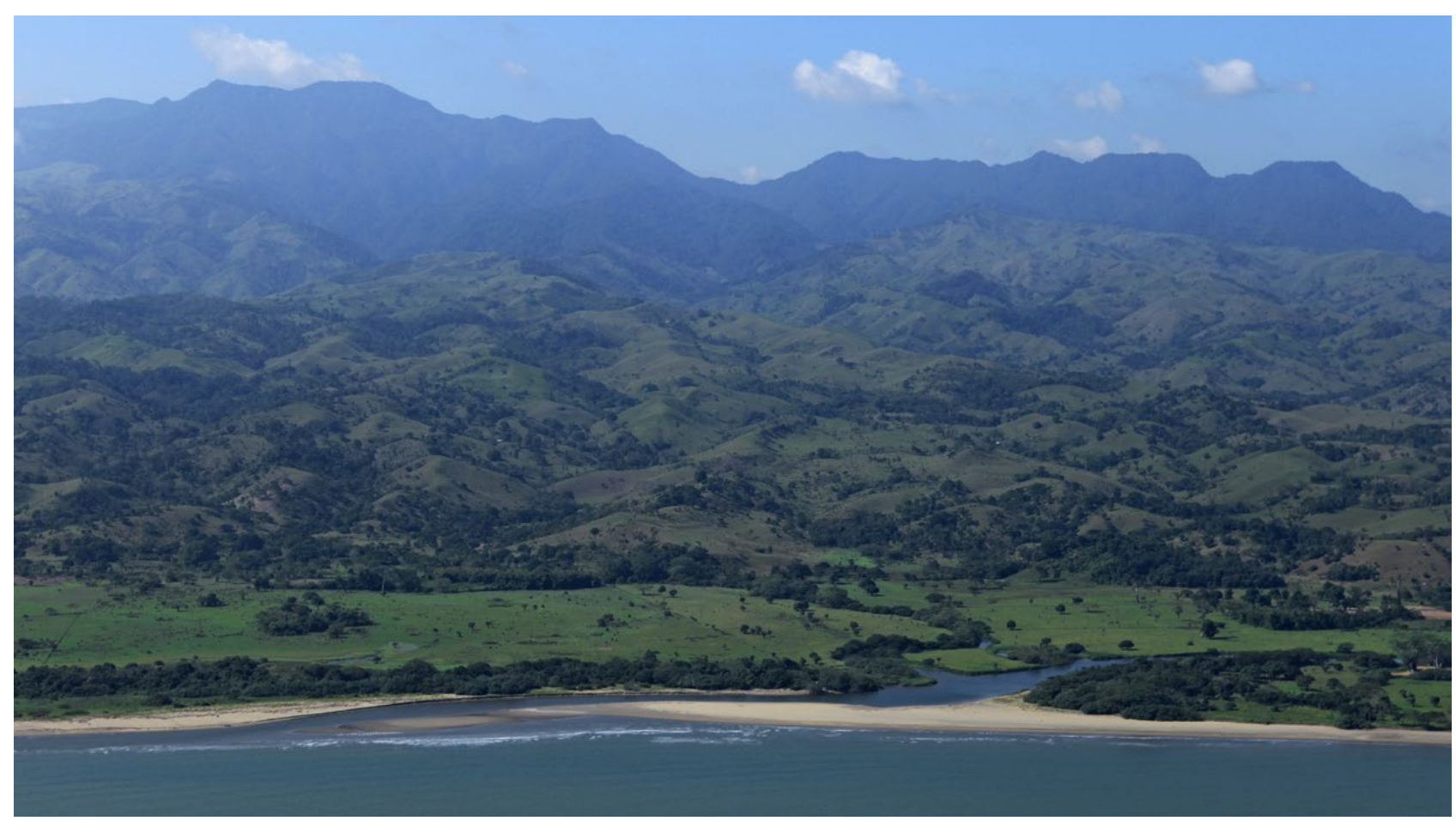

La sierra de Los Tuxtlas desde el mar, al fondo los macizos de Santa Marta y San Martín Tuxtla (fotografía cortesía de Gerardo Sánchez Vigil) 
la selva y los acahuales y a los chaneques, que se apropiaron del espíritu de las vacas, de la caña y de los hombres, transformándose en brujos.

El tiempo y los cambios no mermaron su dominio de los vientos y del agua, sigue manteniendo su ascendencia en los humedales y en la trama de ríos que vinculan las cuencas del Papaloapan y Coatzacoalcos, la puerta de Sotavento, el acceso a las entrañas de Mesoamérica. Los piratas adivinaron el camino hacia la Nueva España, y en su búsqueda, exploraron cuevas, lagunas y ríos, inspirando historias y fábulas de aventuras extraordinarias, de audacia, de tesoros, y ciudades de sueńo, Veracruz, Tlacotalpan, San Juan Evangelista, Campeche.

Durante los embates del clima y de la actividad volcánica, bajo la presión de la población y de muchos períodos de abandono, la selva ha ido $y$ venido, se ha ocultado en lugares inasequibles, desde donde ha recorrido una y otra vez el paisaje, acechando en los acahuales y en los árboles que dejó como vigías, tratando de recuperar sus lares. El pai- saje de la sierra es historia y es cultura, su diversidad fluye inmune a la perturbación. Sigue siendo el Tlalocan que irrumpe en los sueños de la conservación y del desarrollo sustentable de Los Tuxtlas.

La vieja sierra protege los arcanos de su diversidad, y hace que el navío inmóvil en la llanura costera, navegue en el tiempo llevando arcas llenas de secretos de la naturaleza, la selva, la diversidad y el conocimiento, acumulados durante su largo viaje.

Un día, la selva se fue y nos dejó atrás, para dejarnos verla desde fuera de la selva y enseñarnos que el paisaje de la sierra es la selva en movimiento, y mostrarnos que uno de sus secretos más valiosos y mejor guardados de su historia en la sierra es su extraordinaria movilidad, que la hace aparecer siempre distinta, en distintos sitios, que es un cambio aparente, y que manejarla es entenderla, como contribuir a que nunca se detenga en su movimiento.

La sierra de Los Tuxtlas es leyenda, tierra mítica veracruzana. 